\title{
Barriers to the implementation of sepsis guideline in a Canadian pediatric tertiary care centre
}

\author{
Mirkaber Mosavianpour ${ }^{1,2,3}$, Jean-Paul Collet ${ }^{* 1,2,3}$, Hamideh Sarmast ${ }^{4}$, Niranjan Kissoon ${ }^{1,2,3}$ \\ ${ }^{1}$ Department of Paediatrics, University of British Columbia, Vancouver, British Columbia, Canada \\ ${ }^{2}$ British Columbia Children's Hospital, Vancouver, British Columbia, Canada \\ ${ }^{3}$ Child and Family Research Institute, Vancouver, British Columbia, Canada \\ ${ }^{4}$ Department of Education, University of British Columbia, Vancouver, British Columbia, Canada
}

Received: May 30, 2016

DOI: $10.5430 /$ jnep.v6n12p34
Accepted: June 29, $2016 \quad$ Online Published: July 18, 2016

URL: http://dx.doi.org/10.5430/jnep.v6n12p34

\begin{abstract}
Introduction: Adherence to Clinical Practice Guidelines for sepsis can improve care processes and outcomes; however, sepsis guideline adherence is plagued by many barriers. The purpose of this article is to report the perceived barriers for implementing a sepsis guideline at British Columbia's Children Hospital.

Methods: This is a mixed method study. Data were collected from clinicians using a questionnaire that covered 3 major domains and included two open-ended questions. Quantitative data analysis focused on the Mean Overall Barrier Score (MOBS) in each category using descriptive and inferential statistical techniques. Qualitative data were analyzed thematically through deductive and inductive approaches.

Results: A total of 176 clinicians participated in the study. Nurses and physicians were the largest groups of participants (52.7\% and $41.2 \%$, respectively). Nurses perceived more barriers (MOBS: 3.3; 95\% CI: 3.1-3.4) compared to attending physicians (MOBS: 3.6; 95\% CI: 3.3-3.8). The most frequent type of barriers reported was contextual, including environmental and guideline related barriers (MOBS: 3.1; 95\% CI: 2.9-3.3), whereas the least barrier reported was lack of motivation (MOBS: 4.0; 95\% CI: 3.9-4.2). Clinicians who were highly motivated and perceived less environmental barriers were more likely to use the guideline (Odds Ratio of 2.2 [ $p=.036]$ and 2.2 [ $p=.092]$, respectively).

Conclusions: Motivation was the most important predictor of guideline use while contextual barriers hindered use. Therefore, motivating the clinicians and removing external barriers offers the best chance for successful guideline implementation. Furthermore, removing barriers for the use of sepsis guideline among nursing group needs more consideration.
\end{abstract}

Key Words: Barriers, Guideline, Sepsis, Adherence, Implementation, Pediatrics, Nursing

\section{INTRODUCTION}

Severe infections leading to sepsis are among the leading causes of mortality worldwide. ${ }^{[1,2]}$ While early recognition and treatment of sepsis can improve survival, ${ }^{[1-3]}$ the full benefit of therapy has not been realized. This is partly due to the fact that while adherence to Clinical Practice Guidelines $(\mathrm{CPGs})^{[4]}$ may improve care processes and outcomes and decrease costs, ${ }^{[1,3,5,6]}$ low adherence to CPGs still persists. Suboptimal adherence ${ }^{[2,5,7-10]}$ is due to several factors including clinicians disagreement with the content of the guideline, perceived lack of relevance to the patient population or their practice, and resource limitations to implement the guideline. ${ }^{[2,11-14]}$

Low adherence to the sepsis guideline is also an issue at

\footnotetext{
*Correspondence: Jean-Paul Collet; Email: JCollet@cw.bc.ca; Address: Department of Pediatrics, University of British Columbia, Vancouver, British Columbia, Canada.
} 
the British Columbia's Children Hospital (BCCH). In 20062007 a team of clinicians composed of nurses, critical care specialists and pediatricians at $\mathrm{BCCH}$ developed and implemented a sepsis guideline that yielded low adherence rates and was virtually ignored by clinical staff. ${ }^{[2]}$ In 2014, cognizant of this issue we developed a new sepsis guideline based on the AGREE II (Appraisal of Guidelines for Research \& Evaluation II) approach. ${ }^{[2,15]}$ The elements of our guideline were similar to the American College of Critical Care Medicine/Pediatric Advanced Life Support clinical practice guidelines of which was co-authored by one of our authors (NK) ${ }^{[16]}$ At the same time, we conducted a literature review about benefits, pitfalls and possible solutions for the implementation of sepsis guidelines that was reported elsewhere. ${ }^{[3]}$ Meanwhile, in an effort to improve adherence to sepsis guideline, we conducted a survey (present project) to identify the barriers using an accepted framework ${ }^{[17,18]}$ and identify mechanisms to circumvent them when implementing the guideline. The purpose of this manuscript is to report the barriers identified for implementing a sepsis guideline at BCCH. ${ }^{[19]}$ Findings of this study can be useful for various members of multidisciplinary clinical teams who are in the front line of taking care of potential pediatric sepsis patients using clinical practice guidelines, including nurses, physicians, and allied health staff of various secondary, tertiary and quaternary care centers.

\section{MethodS}

This is a nested mixed method transformative study ${ }^{[20,21]}$ conducted at $\mathrm{BCCH}$, the only tertiary pediatric care center in the province of British Columbia serving a population of almost 5 million. ${ }^{[2,19]}$ BCCH serves as a center for clinical care, research and education and is affiliated with the University of British Columbia (UBC). The UBC Research Ethics Board approved the project protocol and waived signing consent for participation (CW11-0236/H11-02266). Data were collected from $\mathrm{BCCH}$ clinicians using a questionnaire ${ }^{[17]}$ that assesses barriers related to three major areas related respectively to knowledge (including two domains of lack of familiarity and lack of awareness), attitudes (including four domains of lack of agreement, lack of outcome expectancy, lack of self-efficacy and lack of motivation) and behavior (especially the domains of contextual barriers composed of environmental and guideline-related factors). ${ }^{[11,17]}$ These three areas were initially proposed by Cabana to asses barriers to the optimal application of guidelines among clinicians and have been widely accepted as a robust method for identifying barriers to guideline adherence. ${ }^{[1,22,23]}$ Domain framework and structure of the questionnaire can be found in Table 1 . The final questionnaire included 32 items composed of the 22

Published by Sciedu Press questions of the original questionnaire, ${ }^{[17]} 7$ demographic questions and three questions to assess additional contextual factors (collaboration in workplace, existing care processes, colleagues' opinion). The qualitative section is nested ${ }^{[20]}$ within quantitative questions and included two open questions to assess the most important incentive and barrier. ${ }^{[20,21]}$

The questionnaire uses a 6-point Likert scale (0-5) ranging from "strongly disagree" to "strongly agree" (higher scores mean fewer barriers). A domain-specific "barrier score" was calculated as the mean value of the item specific scores for the domain, resulting in an overall score between 0 and 5 . Where required, we dichotomized Likert scores, with Likert scores of 0,1, 2 classified as "No" and scores of 3, 4 and 5 classified as "Yes".

Content and face validity of the questionnaire was established by a team of 5 experts including an epidemiologist, pediatrician, health education and behavior modification specialist, critical care specialist and nurse. The internal consistency of the questionnaire was good, as demonstrated by a Cronbach alpha coefficient of 0.81 , when assessed in a pilot study of 16 people. In this study convenient sampling was used. In so doing, we circulated the electronic questionnaire through the hospital clinician email list and the hard copy version by nursing team among all the clinicians in areas where the sepsis tool was intended for use. We encouraged participation by follow-up emails, announcements and phone calls. Participation in the study was voluntary. Data were collected through both REDCap (Research Electronic Data Capture) online data collection system and a paper version of the questionnaire.

Quantitative data were analyzed using descriptive (point estimates and 95\% confidence intervals) and inferential statistical techniques (independent $t$-test, chi-square test and one-way analysis of variance [ANOVA]) using SPSS 16 . We used logistic regression to identify the barriers related to the previous use of the guidelines among various categories of clinicians (nurses, physician and allied health staff).

Answers to open questions were analyzed thematically first using the domains in Table 1, through a deductive coding method. For example, lack of time and lack of staff were both coded as "contextual" barriers (more specifically, environmental). Two coders specialized in guideline implementation, barriers to change, medical anthropology, and medical and nursing education used the qualitative data to categorize the answers into one of the barrier domains or sub-domains using ATLAS ti (qualitative data analysis software), as well as Microsoft Word. Data that did not fit into any of these domains were coded inductively and new codes were assigned to these data. For example, answers such as "Need clinical autonomy 
for decision making" was coded as "power for decision making". Lack of agreement among the coders was discussed with a third person specialized in guideline implementation and behavior modification and final decision was made after discussing with the original coders. After analyzing answers to open-ended questions, findings were given as numbers and percentages by grouping the answers. ${ }^{[20,21]}$ In interpreting the results we used motivation and lack of inertia of previous practice interchangeably. ${ }^{[17]}$

Table 1. Domain framework and structure of the final questionnaire

\begin{tabular}{|c|c|c|c|}
\hline & \multicolumn{2}{|l|}{ Domains } & Number of questions \\
\hline \multirow{2}{*}{$\begin{array}{l}\text { Barriers related } \\
\text { to knowledge }\end{array}$} & \multicolumn{2}{|l|}{ Domain 1: Lack of familiarity } & 1 \\
\hline & \multicolumn{2}{|l|}{ Domain 2: Lack of awareness } & 1 \\
\hline \multirow{4}{*}{$\begin{array}{l}\text { Barriers related } \\
\text { to attitudes }\end{array}$} & \multicolumn{2}{|l|}{ Domain 3: Lack of agreement } & 5 \\
\hline & \multicolumn{2}{|l|}{ Domain 4: Lack of outcome expectancy } & 2 \\
\hline & \multicolumn{2}{|l|}{ Domain 5: Lack of self-efficacy } & 1 \\
\hline & \multicolumn{2}{|l|}{ Domain 6: Lack of motivation } & 1 \\
\hline \multirow{2}{*}{$\begin{array}{l}\text { Barriers related } \\
\text { to behavior }\end{array}$} & \multirow{2}{*}{$\begin{array}{l}\text { Domain 7: } \\
\text { Contextual barriers (including } \\
\text { environmental and guideline factors } \\
\text { altogether) barriers: } 11 \text { questions }\end{array}$} & $\begin{array}{l}\text { Environmental factors (such as lack of time, resources, } \\
\text { reimbursement, organizational constraints and liability) }\end{array}$ & 10 \\
\hline & & $\begin{array}{l}\text { Guideline related barriers (such as characteristics of } \\
\text { guideline and, presence of contradictory guidelines) }\end{array}$ & 1 \\
\hline \multirow{3}{*}{ Other questions } & & Previous use of the BCCH sepsis guideline & 1 \\
\hline & & Demographic questions & 7 \\
\hline & Open ended questions & The most important barrier & 1 \\
\hline \multicolumn{3}{|l|}{ Total } & 32 \\
\hline
\end{tabular}

\section{Results}

\subsection{Demographic characteristic of the participants}

In total 176 people completed the questionnaire. Table 2 shows the distribution of the participants by their demographic characteristics. Nurses and physicians (attending physicians and medical trainees) were the largest groups of participants, with $52.7 \%(87 / 165)$ and $41.3 \%(68 / 165)$, respectively. The majority of the participants $(80.5 \%, 132 / 164)$ were females and mostly in the age group of 20-34 years $(52.1 \%, 85 / 163)$. Most of the respondents $(58.9 \%, 96 / 163)$ did not have a leadership role and the mean work experience in the hospital was 9 years (95\% CI: 7.7-10.4).

\subsection{Barriers domains}

Only $55.7 \%$ (98/176) of the respondents including $66.2 \%$ $(45 / 68)$ of the physicians and $51.7 \%(45 / 87)$ of the nurses were familiar with the guideline. Familiarity with the guideline among the clinicians who played leadership roles (such as program managers, clinical nurse coordinators and medical directors) was significantly higher $(68.7 \%, 46 / 67)$ than frontline clinicians who had no leadership roles $(47.9 \%$, 46/96); $\chi^{2}=6.9 ; \mathrm{df}=1 ; p=.009$.

Table 2. Distribution of the participants by demographic characteristics

\begin{tabular}{|c|c|c|c|}
\hline & & Frequency & Percent (\%) \\
\hline \multirow{6}{*}{ Role } & Nurse & 87 & 52.7 \\
\hline & Physician (Attending physicians and medical trainees) & 68 & 41.3 \\
\hline & Pharmacist & 7 & 4.2 \\
\hline & Respiratory therapist & 2 & 1.2 \\
\hline & Others & 1 & 0.6 \\
\hline & Total & 165 & 100.0 \\
\hline \multirow{3}{*}{ Sex } & Male & 32 & 19.5 \\
\hline & Female & 132 & 80.5 \\
\hline & Total & 164 & 100.0 \\
\hline \multirow{5}{*}{ Age } & 20-34 years & 85 & 52.1 \\
\hline & $35-49$ years & 51 & 31.3 \\
\hline & 50-64 years & 26 & 16.0 \\
\hline & 65 years or older & 1 & 0.6 \\
\hline & Total & 163 & 100.0 \\
\hline \multirow{3}{*}{ Leadership role } & Yes & 67 & 41.1 \\
\hline & No & 96 & 58.9 \\
\hline & Total & 163 & 100.0 \\
\hline
\end{tabular}


The mean overall barrier score (MOBS) among those who were familiar with the guideline was 3.4 (95\% CI: 3.3-3.5). Nurses perceived more barriers (MOBS: 3.3 ; 95\% CI: 3.13.4) compared to attending physicians (MOBS: 3.6; 95\% CI: 3.3-3.8); however, one-way analysis of variance (ANOVA) showed that the difference was not significant in our sample (F: $1.02 ; p=.40, \mathrm{df}=4)$.

Table 3 shows the scores for all domains of the barrier frame- work among those who were familiar with the guideline. The most frequent barriers reported were contextual including environmental factors such as lack of enough resources and guideline related, whereas the least reported was lack of motivation (MOBS: 3.1 and 4.0, respectively). In addition, answers by 49 individuals to open questions confirmed that most of the reported barriers $(53.1 \%, 26 / 49)$ were related to contextual factors, including environment $(38.8 \%, 19 / 49)$ and guideline related $(14.3 \%, 7 / 49)$ (see Table 4$)$.

Table 3. Mean barrier score of the domains (higher score means fewer barriers) $(\mathrm{N}=98)$

\begin{tabular}{|c|c|c|c|c|}
\hline & \multirow{2}{*}{ Domain } & \multirow{2}{*}{ Mean } & \multicolumn{2}{|l|}{$95 \% \mathrm{CI}$} \\
\hline & & & Lower Bound & Upper Bound \\
\hline \multirow{2}{*}{ Knowledge } & Lack of familiarity & 3.4 & 3.3 & 3.6 \\
\hline & Lack of awareness & 3.7 & 3.5 & 3.8 \\
\hline \multirow{3}{*}{ Attitudes } & Lack of agreement & 3.8 & 3.7 & 3.9 \\
\hline & Lack of outcome expectancy & 3.1 & 2.9 & 3.3 \\
\hline & lack of self-efficacy & 3.5 & 3.3 & 3.7 \\
\hline \multirow{3}{*}{ Behavior } & Contextual barriers (including environmental and guideline factors altogether) & 3.1 & 3.0 & 3.2 \\
\hline & Contextual barriers: environmental factors & 3.1 & 3. 3 & 3.2 \\
\hline & Contextual barriers: guideline factors & 3.2 & 3.0 & 3.4 \\
\hline
\end{tabular}

Table 4. Most frequent barrier to the use of $\mathrm{BCCH}$ sepsis guideline

\begin{tabular}{llll}
\hline & & Frequency & Percent (\%) \\
\hline Contextual & Guideline barriers & 7 & 14.3 \\
barriers & Environmental barriers & 19 & 38.8 \\
Familiarity & & 23 & 46.9 \\
Total & & 49 & 100.0 \\
\hline
\end{tabular}

Seventy percent of the nurses (26/37) and $64.1 \%$ of the physicians (25/39) who were familiar with the guideline mentioned that they had used it. These clinicians reported significantly fewer barriers to its use as compared to those who never used the guideline before (MOBS: $3.5 ; 95 \% \mathrm{CI}$ : 3.4-3.7 vs. 3.2; 95\% CI: 3.1-3.4; $t=-2.61$, df $=81, p=$ $.011)$. The differences between users and non-users of the guideline were significant for domains of awareness, lack of agreement, lack of motivation and contextual factors (see Table 5). These findings were used to develop a predictive model for the previous use of the guideline. The final model indicated that clinicians who were highly motivated (OR: $2.2 ; p=.036)$ and perceived less environmental barriers (OR: $2.2 ; p=.092$ ) were more likely to use the guideline.

In response to the open questions, the most important incentive to use the guideline was expected improved outcomes mentioned by $52.9 \%$ of the staff (37/70). A few other incentives emerged that included autonomy to apply the guideline, power for decision making about care plan and the way CPG is presented in the unit (see Table 6).

Table 5. Relationship between previous use of the sepsis guideline and various barrier domains

\begin{tabular}{|c|c|c|c|c|c|}
\hline & \multicolumn{2}{|c|}{ Levene's Test for assuring equality of variances } & \multicolumn{3}{|c|}{ t-test for Equality of Means } \\
\hline & \multirow{2}{*}{$\mathbf{F}$} & \multirow{2}{*}{ Sig. } & \multirow{2}{*}{$t$} & \multirow{2}{*}{ df } & Sig. \\
\hline & & & & & (2-tailed) \\
\hline Lack of familiarity & 0.106 & 0.746 & -1.915 & 81 & 0.059 \\
\hline Lack of awareness & 1.519 & 0.221 & -2.396 & 81 & 0.019 \\
\hline Lack of agreement & 2.367 & 0.128 & -2.244 & 81 & 0.028 \\
\hline Lack of outcome expectancy & 0.003 & 0.954 & -1.317 & 81 & 0.192 \\
\hline Lack of self-efficacy & 0.021 & 0.884 & -1.701 & 78 & 0.093 \\
\hline Lack of motivation & 1.447 & 0.232 & -2.824 & 80 & 0.006 \\
\hline $\begin{array}{l}\text { Contextual barriers (including environmental and } \\
\text { guideline factors) }\end{array}$ & 0.03 & 0.864 & -2.052 & 81 & 0.043 \\
\hline Contextual barriers: environmental factors & 0.062 & 0.803 & -2.225 & 81 & 0.029 \\
\hline Contextual barriers: guideline factors & 3.408 & 0.069 & 0.76 & 75 & 0.45 \\
\hline
\end{tabular}


Table 6. Most important incentive for using the $\mathrm{BCCH}$ sepsis guideline

\begin{tabular}{lll}
\hline & Frequency & Percent (\%) \\
\hline Outcome expectancy & 37 & 52.9 \\
High quality guideline & 10 & 14.3 \\
Lack of environmental barriers & 14 & 20.0 \\
$\begin{array}{l}\text { Familiarity with guideline } \\
\begin{array}{l}\text { Other factors (autonomy to apply, } \\
\text { power for decision making, how CPG }\end{array}\end{array}$ & 4 & 5.7 \\
$\begin{array}{l}\text { is presented in the unit) } \\
\text { Total }\end{array}$ & 70 & 7.1 \\
\hline
\end{tabular}

\section{Discussion}

We reported the advantages, barriers and solutions for the implementation of sepsis guideline elsewhere based on literature review and expert opinions. ${ }^{[3]}$ We have also reported the process of improving $\mathrm{BCCH}$ sepsis guideline in another study. ${ }^{[2]}$ As a follow up, we conducted the present study in order to identify barriers for the use of sepsis guideline at $\mathrm{BCCH}$. We found that around half $(44.3 \%)$ of the respondents, including about half of the nurses $(48.3 \%)$ and one third of the physicians $(33.8 \%)$ were not familiar with $\mathrm{BCCH}$ sepsis guideline, which would result in underutilization of the guideline. Even though familiarity does not guarantee that the guideline will be used, lack of familiarity usually results in non-utilization. ${ }^{[2,3,24,25]}$ Nursing and physician groups are the main members of multidisciplinary care teams and play a critical role in guideline implementation. ${ }^{[2,3]}$ The lack of familiarity with guidelines among both nurses ${ }^{[7]}$ and physicians ${ }^{[7,26]}$ has been shown as an important barrier to the guideline application. ${ }^{[2,7,26]}$

In contrast, clinicians who played leadership roles (such as program managers, clinical nurse coordinators and medical directors) were significantly more familiar with sepsis guideline compared to other clinicians (such as frontline staff and opinion leaders). This may be due to involvement of these leaders in guideline development to a greater extent than other stakeholders. In fact, the BCCH sepsis guideline was developed by a few clinical leaders only, which confirms this assertion. ${ }^{[2]}$ In our previous report we recommended stakeholders' involvement in developing guidelines as key factor for the successful implementation of sepsis guideline at $\mathrm{BCCH} \cdot{ }^{[2]}$ Greater familiarity of the clinical leaders with the guideline may also be related to better integration and improved communication of these staff as compared to frontline workers. In general, integrated individuals, can have sooner access to information because they are closely aligned with most individuals in their community of practice. ${ }^{[27-30]}$

The finding that nurses perceived more barriers to the use of the guideline than attending physicians, although statistically not significant, is important for implementation as nurses are usually the frontline professionals to assess, triage and start emergent treatment for sepsis. ${ }^{[31]}$ Therefore, in the implementation phase, we may need to pay more attention to the identification and removal of the barriers to the use of guidelines among this group. One multicenter study in 27 hospitals showed that more than $90 \%$ of physicians, administrators, and pharmacists, as well as $96 \%$ of nurses assigned primary responsibility for patient safety to nurses. ${ }^{[7]}$

Our study showed that contextual barriers were the most frequently reported barriers to implementation, whereas lack of motivation represented the least frequent challenge. In addition, our predictor model showed that clinicians who are highly motivated are more likely to use the guideline. This indicates that strong motivation may overcome contextual barriers on the application of the guideline. Therefore, an important approach for successful implementation of the guideline is to motivate the clinicians (nurses, physicians and allied health), and the best way is to involve them in the development and implementation of the guideline..$^{[2,3]}$ One effective way to motivate frontline clinicians such as nurses is through the development of communities of practice around guideline implementation. ${ }^{[3]}$ More involvement creates opportunities for working in teams and is associated with considerably more guideline adherence compared to non-team model ( $80 \%$ vs. $40 \%$, respectively). ${ }^{[3]}$ In addition, it is important to mitigate contextual barriers especially environmental barriers such as lack of enough resources because these barriers can derail successful implementation and may demotivate staff. Learning from our experience, we have developed a list of recommendations that can be found in Table 7. Future research needs to be implemented in order to explore if following these recommendations and addressing barriers identified in this study will improve adherence to the guidelines and subsequently improve clinical outcomes. These findings can also be helpful in other healthcare centers (secondary, tertiary and quaternary) especially for nurses as frontline professionals for starting emergent sepsis management process ${ }^{[31]}$ through the implementation of sepsis guideline.

Findings of this study should be interpreted considering a few limitations. First, we used convenient sampling in our study. Second, qualitative data were collected through open questions and not through interviews or observations. In addition, we have only considered barriers reported in Cabana's model. Other models may suggest different types of barriers to be considered for implementing guidelines. However, we believe that these limitations have not detracted from the aims and findings of our study. 
Table 7. List of recommendations for facilitating implementation of guidelines

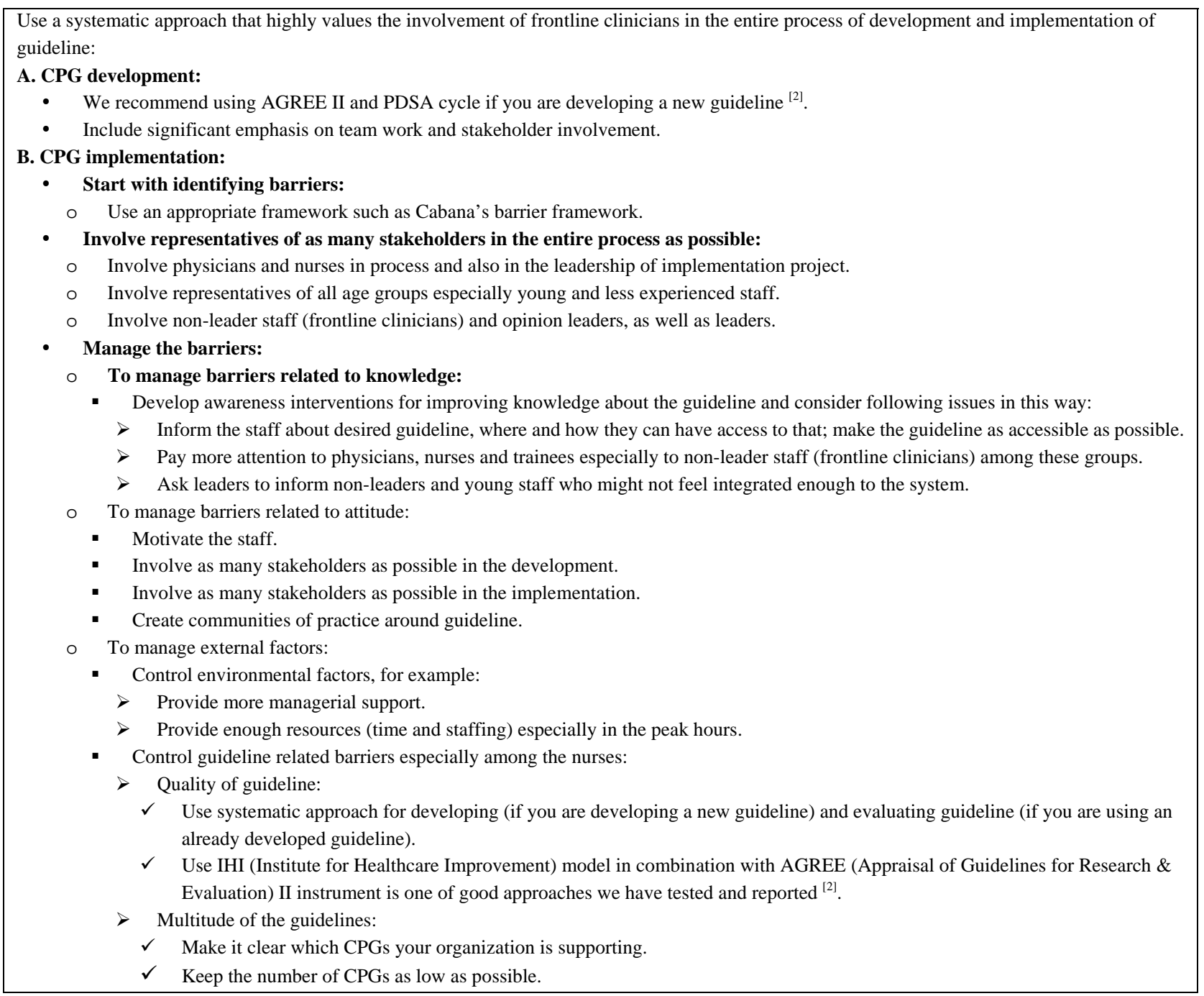

\section{Conclusion}

Even though contextual factors were the most frequently reported barriers, motivation was the most important factor determining if the guidelines will be used. Therefore, motivating the clinicians such as nurses, physicians and allied health for using the guideline may better improve their application. In addition, it is important to account for and control contextual barriers as much as possible. Furthermore, removing barriers for the use of sepsis guideline among nurses, as the starters of managing potential sepsis cases, needs more consideration.

\section{CONFLicts OF InTEREST Disclosure}

The authors declare that they have no conflicts of interest.

\section{REFERENCES}

[1] Kissoon N, Carapetis J. Pediatric sepsis in the developing world. J Infect. Elsevier Ltd; 2015; 71: S21-S26.

[2] Mosavianpour M, Collet JP, Sarmast HH, et al. A quality driven process for developing sepsis practice guideline. Indian J Appl Sci. 2015; 5(10): 344-353.

[3] Kissoon N. Sepsis guideline implementation: benefits, pitfalls and possible solutions. Crit Care. 2014; 18: 207. http://dx.doi.org

\section{$/ 10.1186 / \mathrm{cc} 13784$}

[4] Plambech MZ, Lurie AI, Ipsen HL. Initial, successful implementation of sepsis guidelines in an emergency department. Dan Med J. 2012; 59(12): 1-5. PMID: 23290285

[5] Teije A, Miksch S, Lucas P, editors. Computer-based Medical Guidelines and Protocols: A Primer and Current Trends. Amsterdam, Berlin, Oxford, Tokyo, Washington, DC: IOS Press; 2008. PMid:18824335 
[6] Mazza D, Chapman A, Michie S. Barriers to the implementation of preconception care guidelines as perceived by general practitioners: a qualitative study. BMC Health Serv Res. 2013 Jan; 13(1): 36. PMid:23368720 http://dx.doi.org/10.1186/147 2-6963-13-36

[7] Abrahamson KA, Fox RL, Doebbeling BN. Facilitators and barriers to clinical practice guideline use among nurses. Am J Nurs [Internet]. 2012; 112(7): 26-35; quiz 46, 36. Available from: http: //www.ncbi.nlm.nih.gov/pubmed/22705494

[8] Turner T, Misso M, Harris C, et al. Why Don't Physicians Follow. Access. 2008; 8: 1-8.

[9] Koh SSL, Manias E, Hutchinson AM, et al. Nurses ' perceived barriers to the implementation of a Fall Prevention Clinical Practice Guideline in Singapore hospitals. BMC Health Serv Res. 2008; 10 : 1-10. http://dx.doi.org/10.1186/1472-6963-8-105

[10] Yagasaki K, Komatsu H. Preconditions for Successful Guideline Implementation: Perceptions of Oncology Nurses. BMC Nurs [Internet]. BioMed Central Ltd; 2011; 10(1): 23. Available from: http://www. biomedcentral.com/1472-6955/10/23

[11] Cabana MD. Why Don't Physicians Follow Clinical Practice Guidelines?: A Framework for Improvement. J Am Med Assoc. 1999 Oct 20; 282(15): 1458-1465. PMid:10535437 http://dx.doi.org/1 $0.1001 /$ jama. 282.15 .1458

[12] Tudiver F, Herbert C, Goel V. Why don't family physicians follow clinical practice guidelines for cancer screening? J Am Board Fam Pract. 1998; 159(7).

[13] Ali ZH, Taha NM. Effect of nursing guideline for recently diagnosed hypertensive patients on their knowledge, self-care practice and expected clinical outcomes. J Nurs Educ Pract [Internet]. 2014; 5(3): 1-11. Available from: http://www.scie du.ca/journal/index.php/jnep/article/view/4595 http: //dx.doi.org/10.5430/jnep.v5n3p1

[14] Jeffs L, Beswick S, Lo J, et al. Hospitalnurses' perceptions associated with implementing multiple guidelines: A qualitative study. J Nurs Educ Pract [Internet]. 2012; 3(2): 31-40. Available from: http://www.sciedu.ca/journal/index.php/jn ep/article/view/1541 http://dx.doi.org/10.5430/jnep. v3n2p31

[15] Brouwers MC, Kho ME, Browman G, et al. AGREE II: Advancing guideline development, reporting, and evaluation in health care. Prev Med (Baltim). Elsevier Inc.; 2010; 51(5): 421-424.

[16] Brierley J, Carcillo JA, Choong K, et al. Clinical practice parameters for hemodynamic support of pediatric and neonatal septic shock: 2007 update from the American College of Critical Care Medicine. Crit Care Med [Internet]. 2009; 37(2): 666-88. Available from: http://www.pubmedcent ral.nih.gov/articlerender.fcgi?artid $=4447433 \& t$ ool=pmcentrez\&rendertype=abstract PMid:19325359 http://dx.doi.org/10.1097/CCM.0b013e31819323c6

[17] Larson E. A tool to assess barriers to adherence to hand hygiene guideline. Am J Infect Control. 2004 Feb; 32(1): 48-51. PMid:14755236 http://dx.doi.org/10.1016/j.ajic.2003.05.005
[18] Bokhoven M, Kok G, Weijden T. Designing a quality improvement intervention: a systematic approach. Qual Saf Heal Care. 2003; 215 220. PMid:12792013

[19] BCStats. BC Stats [Internet]. BC population. 2015 [cited 2016 Feb 3]. p. Featured Publications. Available from: http://www. bcstat s.gov.bc.ca/Home. aspx

[20] Holloway I, Wheeler S. Qualitative research in nursing and healthcare. 3rd ed. Iowa, USA: Wiley-Blackwell; 2010.

[21] Driscoll DL, Salib P, Rupert DJ. Merging Qualitative and Quantitative Data in Mixed Methods Research: How To and Why Not. Ecol Environ Anthropol. 2007; 3: 18-28.

[22] Cabana MD, Rushton JL, Rush AJ. Implementing practice guidelines for depression: applying a new framework to an old problem. Gen Hosp Psychiatry. 2002; 24(1): 35-42. http://dx . doi .org/10. 10 16/S0163-8343(01)00169-4

[23] Larson E. A tool to assess barriers to adherence to hand hygiene guideline. Am J Infect Control [Internet]. $2004 \mathrm{Feb}$ [cited 2012 Mar 9]; 32(1): 48-51. Available from: http://www.ncbi.nlm.nih.g ov/pubmed/14755236

[24] van der Veer SN, Tomson CR V, Jager KJ, et al. Bridging the gap between what is known and what we do in renal medicine: improving implementability of the European Renal Best Practice guidelines. Nephrol Dial Transplant [Internet]. 2014; 29(5): 951957. http://ndt.oxfordjournals.org/cgi/doi/10.1093/n dt/gft496 PMid:24353322

[25] Timmermans S. From autonomy to accountability: the role of clinical practice guidelines in professional power. Perspect Bol Med [Internet]. 2005; 48(4): 490-501. Available from: http://www.ncbi.n Im.nih.gov/pubmed/16227662

[26] Cabana MD. Why Don't Physicians Follow Clinical Practice Guidelines?: A Framework for Improvement. JAMA. 1999 Oct 20; 282(15): 1458-1465. http://dx.doi.org/10.1001/jama.282.15.1458

[27] Valente TW. Social Networks and Health. New York: Oxford University Press; 2010. http://dx.doi.org/10.1093/acprof : oso/9780195301014.001.0001

[28] Merrill J, Hripcsak G. Using Social Network Analysis within a Department of Biomedical Informatics to Induce a Discussion of Academic Communities of Practice. J Am Med Informatics Assoc. 2008; 15(6): 780-783. PMid:18756000 http://dx.doi.org/10.1197 /jamia.M2717

[29] Ma X, Chen G, Xiao J. Analysis of an online health social network. Proc 1st ACM Int Heal informatics Symp [Internet]. 2010; 297-306. Available from: http://dl.acm.org/citation. $\mathrm{cfm}$ ? id=18830 35

[30] Bridewell W, Das AK. Social network analysis of physician interactions: the effect of institutional boundaries on breast cancer care. AMIA Annu Symp Proc [Internet]. 2011 Jan; 2011: 152-60. Available from: http: //www.pubmedcentral.nih.gov/articlerender.fcgi ?artid=3243165\&tool=pmcentrez\&rendertype=abstract

[31] March A. Facilitating Implementation of Evidence-Based Evidencebased guidelines in hospital settings: learning from trauma centers. 2006. 